\title{
Developing productive relationships with partner schools to widen participation. A Practice Report
}

Judy Skene

Student Services

The University of Western Australia

\begin{abstract}
The Review of Australian Higher Education noted the unacceptably low participation rates of students from low socio-economic status (SES) backgrounds, Indigenous students and rural and remote students in higher education. These students are particularly under-represented in Group of Eight universities like The University of Western Australia (UWA). This nuts and bolts session focuses on strategies for developing productive relationships with partner schools to widen participation. The Aspire UWA program has partnerships with 24 under-represented schools: six in the Pilbara region of Western Australia and 18 in outer-metropolitan Perth. Aspire UWA aims to raise aspirations for tertiary study, starting with Year 9 students and working closely with them, their schools, families and communities through to successful transition to university. This session shares ideas to support all these different stakeholders long term and, in the case of the Pilbara, across vast distances, to achieve positive outcomes.
\end{abstract}

\section{Please cite this practice report as:}

Skene, J. (2010). Developing productive relationships with partner schools to widen participation. A Practice Report. The International Journal of the First Year in Higher Education, 1(1), 77-83.

This practice report has been accepted for publication in Int J FYHE. Please see the Editorial Policies under the 'About' section of the Journal for further information.

(C) Copyright of practice reports is retained by authors. As an open access journal, practice reports are free to use, with proper attribution, in educational and other non-commercial settings. ISSN: $1838-2959$ 


\section{Introduction}

The Review of Australian Higher Education (Bradley, Noonan, Nugent \& Scales, 2008) noted the unacceptably low participation rates of students from low socio-economic status (SES) backgrounds, Indigenous students and rural and remote students in higher education. The participation rate nationally has not changed significantly in the past fifteen years. These students are particularly under-represented in Group of Eight universities like The University of Western Australia (UWA) (James, 2007). There are complex reasons why both access and retention of low SES students has challenged universities in Australia that are beyond the scope of this brief paper. Suffice to say that there is recognition that meeting the national target of the federal government will require sustained relationships with schools to develop the integrated strategies necessary to address cultural change where aspirations are low or provide support and advice where there are perceived and real barriers to participation (National Centre for Student Equity in Higher Education, 2009).

\section{Overview of the Aspire UWA program}

The University of Western Australia committed to an ambitious outreach program in 2009 to contribute to the shared national goal of 20 per cent of low SES students enrolments in undergraduate higher education by 2020 (Bradley et al., 2008). Aspire UWA aims to raise aspirations and improve academic readiness of students in high schools with a low transfer to higher education. It is funded by the Australian Government, Department of Education, Employment and Workplace Relations and the University and supported by a growing number of external stakeholders such as The Smith Family and the Pilbara Development Commission. In 2009, Aspire UWA formed partnerships with six schools in the Pilbara region and 18 schools in Outer Metropolitan Perth that are located in a low socio-economic area, have a significant Indigenous student population and/or groups of students drawn from new and emerging communities.

Although in its early stages, the Aspire UWA program has been received enthusiastically by the partner schools. The program has a "whole of university" approach but the key internal UWA stakeholders are Student Services, the School of Indigenous Studies and the Faculty of Medicine, Dentistry and Health Sciences. The program works with Year 9 students initially and follows them through to transition to higher education, each year adding a new cohort of Year 9 students. In addition, the Faculty of Medicine, Dentistry and Health Sciences works with those students in Years 10-12 who have an interest in Medicine or Dentistry. There is a separate quota for these students who must meet standard entry requirements but are then competing in a smaller pool of prospective entrants: an initiative that has received strong endorsement from the schools and parents. Figure 1 below illustrates how the program grows annually with each new cohort added. 
Stage 1: Development (April - September 2009)

School Partnerships / materials / Stakeholder relationships / Launch and Project Documents Launch (21 ${ }^{\text {st }}$ September 2009)

\section{Stage 2: 2009 Outreach (October - December 2009)}

(Provided by: Student Services, School of Indigenous Studies, Faculty of Medicine and Dentistry, Students Ambassadors and other UWA faculties

Year 9 students

(Campus \& school visits)
OMP: Support Years

$10,11 \& 12$ students through to Medicine or Dentistry
SIS: outreach / campus activities / camps for Indigenous students

\section{Review and provide annual report to DEEWR}

Stage 3: 2010 Outreach (January - December 2010)

Provided by: Student Services, School of Indigenous Studies, Faculty of Medicine and Dentistry, Students Ambassadors and other UWA faculties

Year 9 \& 10 students
(Campus \& school
visits)
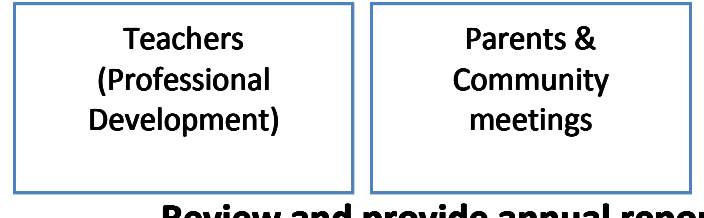
OMP: Support Years $10,11 \& 12$ students through to Medicine or Dentistry

SIS: outreach / campus activities / camps for Indigenous students

\section{Review and provide annual report to DEEWR}

\section{Stage 4: 2011 Outreach (January to December 2011)}

Provided by: Student Services, School of Indigenous Studies, Faculty of Medicine and Dentistry, Students Ambassadors and other UWA faculties

Year $9,10 \& 11$
students
(Campus \& school
visits)

\begin{tabular}{c} 
Teachers \\
(Professional \\
Development) \\
\hline
\end{tabular}

Parents \&
Community
meetings

OMP: Support Years $10,11 \& 12$ students through to Medicine or Dentistry

SIS: outreach / campus activities / camps for Indigenous students

\section{Review and provide annual report to DEEWR}

Figure 1 Aspire UWA program stages

Aspire UWA team members recognise that it is not enough just to focus on activities with the students: relationships need to be developed with principals, teachers, year coordinators, careers advisors, Aboriginal Education Officers and other key staff in schools; with families and with influential members of the school's community. It is this aspect of building sustainable relationships that is the focus of this Nuts \& Bolts session.

To ensure that partner school principals and teachers are included in planning and that the program is responsive to their needs, teacher reference groups for Perth and the Pilbara have been included in the organisational structure. In addition, the program's Reference Group 
includes some representatives from schools and District Education offices, as in Figure 2 below.

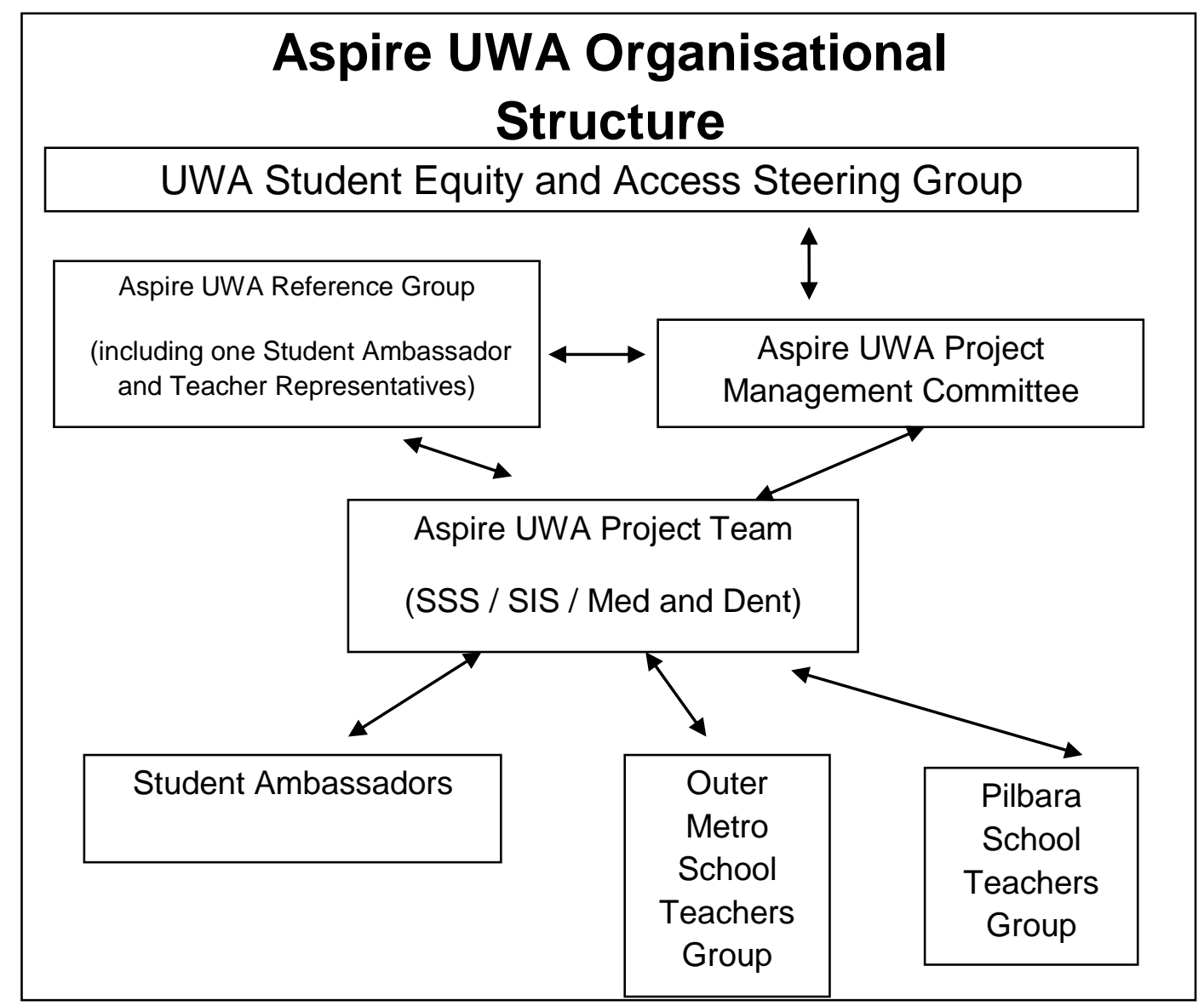

Figure 2 Aspire UWA organisational structure

Further strategies to enhance relationships with other key staff in schools are being developed. At the same time, the program team is looking at ways to build relationships with families and key community groups and individuals who might play influential roles in assisting young people to choose appropriate pathways for themselves post-school. 


\section{Key Questions for discussion}

1. How do we develop meaningful and sustained relationships with partner schools?

Issues to consider:

- Challenges of distance (i.e. Pilbara region 1,000 -1,500 kilometres from university)

- Transient school staff

- School staff already time poor

- Other challenges

\section{Outcomes of the discussion:}

A productive relationship is centred on trust and willingness to engage with partner schools on their terms. The principal and teachers need to feel that there is benefit for their students or they will not want to divert time from their already hectic schedule to accommodate requests from universities for access to their students. Some of the strategies raised in discussion or used by Aspire UWA included:

- Keeping key staff members informed through copying relevant staff and principal into communications;

- Developing activities that fit in with the focus of curriculum;

- Setting up activities so that the teachers can enjoy the event but have as little to do as possible beyond duty of care for their pupils;

- Including teachers in program reference group so that they are represented and have feedback directly into program development;

- Providing some professional development for teachers where possible, to ensure that they feel valued and supported and that activities are building their skills;

- Giving positive feedback about their students when they have engaged in activities;

- Using Student Ambassadors who are former pupils of the school to talk to current students about their own studies at university. Aspire UWA uses Ambassadors as camp leaders for students visiting Perth from the Pilbara, as leaders during on campus activities, and they come out with staff to conduct activities in partner schools, helping students to do the activities and chatting with them. Ambassadors also take a leading role in official events such as the program launch where they introduced all the key speakers. This activity allowed the principals in the audience to share in the success of their former students.

2. How do we work with families and communities to engage them in supporting the aspirations of young people for higher education?

Issues to consider:

- Building trust

- Culturally appropriate communication

- What additional resources might be available: corporate support, NGOs, philanthropic groups, community leaders, cultural groups, etc. 
- Other resources

Outcomes of the discussion:

It was acknowledged that there are key influences beyond the school on young peoples' aspirations for post-secondary pathways. Families and communities, including peers, can have a significant influence on decision-making. Some of the strategies noted were:

- Providing information sessions in the evening or at times appropriate for families to attend;

- Sending a letter to parents with invitation to make contact, view a website or attend a regular "twilight" information session on campus with every child who attends an activity, either on campus or when the program visits a school;

- Making contact with key community groups to identify influential members who can help provide opportunities to reach families;

- Working in partnership with other organisations such as The Smith Family to provide more comprehensive support and avoid duplication;

- Holding activities that are culturally appropriate and are inclusive in their design.

\section{Aspire UWA}

The program has had very positive feedback from its partner schools to date. Schools appreciate that activities start with Year 9 students and continue until Year 12 and that the activities are multi-faceted, layered and comprehensive in their approach. Small gestures can help foster the relationship. For example, Aspire UWA has been conducting Year 10 activities in partner schools in Perth over the past few months. When the team visits, they bring along muffins or something similar to contribute to morning tea in the staff room so that all teachers at the school know they have visited and appreciate the gesture.

During the Pilbara camp, one session is held at the Perth Zoo and while students are in care of zoo-keepers and Student Ambassadors, all the teachers and the team meet in the coffee shop. Aspire UWA buys the coffee and listens to the teachers' feedback on the current camp and what they would like when the team visits them in the Pilbara, or when they come down on camp again. These are small gestures but teachers really appreciate being involved in planning from the start.

In the future, Aspire UWA would like to recruit additional staff from culturally diverse backgrounds who can facilitate the relationship with community groups. The School of Indigenous Studies at UWA is a partner in Aspire UWA and has excellent relationships with community groups but the aim would be to develop similar links with new and emerging communities. 


\section{References}

Bradley, D., Noonan, P., Nugent, H. \& Scales, B. (2008). Review of Australian higher education. Final report. Canberra, Australia: Commonwealth of Australia. Available at

http://www.deewr.gov.au/HigherEducation/Review/Pages/ReviewofAustralianHigher EducationFinalReport.aspx

James, R. (2007). Social equity in a mass, globalised higher education environment: The unresolved issue of widening access to university. Centre for Studies in Higher Education, University of Melbourne. Retrieved on November 17, 2007, from http://www.cshe.unimelb.edu.au/people/staff_pages/James/James.html

National Centre for Student Equity in Higher Education. (2009). Interventions early in school as a means to improve higher education outcomes for disadvantaged (particularly low SES) students. Retrieved on February 8, 2010, from http://www.deewr.gov.au/HigherEducation/Publications/Pages/InterventionsEarlyInS chool.aspx 